\title{
Adversity Quotient Mahasiswa Baru yang Mengikuti Kurikulum Berbasis Kompetensi
}

\author{
Nita Fitria, Taty Hernawaty, Nur Oktavia Hidayati \\ Fakultas Keperawatan Universitas Padjadjaran \\ E-mail: nita_fitria2001@yahoo.com
}

\begin{abstract}
Abstrak
Adversity Quotient (AQ) merupakan suatu bentuk pengukuran yang digunakan untuk mengetahui kemampuan seseorang dalam merespons suatu tantangan atau kesulitan dalam kehidupannya untuk mencapai suatu keberhasilan. Salah satu tantangan dan kesulitan bagi mahasiswa keperawatan adalah menghadapi program Kurikulum Berbasis Kompetensi (KBK) dengan Metode Student Centered Learning (SCL). Tujuan penelitian ini untuk mengetahui gambaran Adversity Quotient mahasiswa baru yang sedang mengikuti Kurikulum Berbasis Kompetensi dengan Metode Student Centered Learning (SCL). Metode penelitian yang digunakan adalah metode deskriptif kuantitatif. Teknik sampling yang digunakan adalah total populasi dengan jumlah sampel 142 orang mahasiswa. Alat ukur yang digunakan dalam penelitian ini adalah modifikasi dari Adversity Response Profile Quick Take ${ }^{\mathrm{TM}}$. Hasil penelitian didapatkan Adversity Quotient mahasiswa baru yang sedang mengakui KBK dengan metode SCL adalah sebagian besar responden yaitu 87 orang $(61,27 \%)$ pada kelompok climber, sebagian kecil dari responden yaitu 50 orang $(35,21 \%)$ pada kelompok transisi camper ke climber, sebagian kecil dari responden yaitu 5 orang $(3,52 \%)$ pada kelompok camper, tidak seorang pun responden yaitu 0 orang $(0.00 \%)$ pada kelompok transisi quitter ke camper dan tidak seorang pun responden yaitu 0 orang $(0.00 \%)$ pada kelompok quitter. Mahasiswa pada posisi climber melihat masalah yang ada saat menjalani program profesi sebagai tantangan.
\end{abstract}

Kata kunci: Adversity quotient, mahasiswa, student centered learning.

\section{Adversity Quetient of New Enrolled Students with Competency Based Curriculum}

\begin{abstract}
Adversity Quotient (AQ) is a form of measurement that used to determine a person's ability to respond of challenges or difficulties as part of achieving a success in life. The challenges and difficulties for nursing students occurred when Competency-Based Curriculum (CBC) has applied using Student Centered Learning (SCL) method. The purpose of this study was to explore the Adversity Quotient Force of nursing students from class of 2011 who applied CBC and SCL as their study method. The research method was descriptive quantitative. Samples were 142 nursing student from class of 2011 who chosen by total sampling technique. The data were collected using a modification of the Adversity Response Profile Quick TakeTM tools. The result showed the majority of Adversity Quotient of respondent who attended CBC with SCL method was in climber categories with 87 people $(61.27 \%)$. The second majority was transition to a camper climber with 50 people $(35.21 \%)$, and then followed by camper, camper quitter, and quitter with 5 persons $(3.52 \%), 0(0.00 \%), 0(0.00 \%)$, respectively.
\end{abstract}

Key words: Adversity quotient, students, student centered learning. 
Nita Fitria : Gambaran Adversity Quotient Mahasiswa Baru

\section{Pendahuluan}

Konteks Teacher Centered Learning (TCL), spoon-feeding bagi para peserta didik tidak lagi sesuai karena proses pembelajaran bersifat lamban dan para peserta didik tidak mempunyai peluang untuk memilih metode pembelajaran yang sesuai. Kelambanan proses pembelajaran yang terjadi didalam paradigma metode TCL dapat menyebabkan peserta didik tertinggal di belakang, tidak dapat menyesuaikan diri dengan kemajuan zaman. Untuk mengatasi kelambanan dan ketertinggalan maka proses pembelajaran perlu diubah, dari one-way traffic menjadi two-way traffic dan interaktif. Dengan menggunakan pembelajaran interaktif para peserta didik dapat diajak bersama-sama secara aktif untuk mencari, menemukan, mengolah, membangun dan memaknai ilmu pengetahuan yang diminati. Pembelajaran interaktif merupakan salah satu karakteristik metode Student Center learning (SCL).

SCL merupakan strategi pembelajaran yang menempatkan peserta didik sebagai subjek atau peserta didik menjadi aktif dan mandiri, dengan kondisi psikologik sebagai adult learner, bertanggung jawab penuh atas pembelajaran, serta mampu belajar beyond the classroom. Dengan prinsip-prinsip ini maka para peserta didik diharapkan memiliki dan menghayati jiwa life-long learner serta menguasai hard skills dan soft skills yang saling mendukung. Disisi lain, para dosen beralih fungsi menjadi fasilitator, termasuk sebagai mitra pembelajaran bagi peserta didik, tidak lagi sebagai sumber pengetahuan utama.

Student Center learning telah mempunyai beberapa metode pembelajaran, salah satunya adalah Problem Based Learning (PBL). Pada umumnya metode PBL ini dipahami sebagai suatu strategi instruksional, kemudian peserta didik mengidentifikasi pokok permasalahan yang dimunculkan secara spesifik. Pokok persoalan tersebut membantu dan mendorong peserta didik untuk lebih memahami mengenai konsep yang mendasari permasalahan yang muncul serta prinsip pengetahuan lain yang relevan. PBL merupakan suatu metode pembelajaran bagi peserta didik. Peserta didik sejak awal dihadapkan pada suatu masalah, setelah itu diikuti oleh proses pencarian informasi yang bersifat student-centered. Dalam PBL, content dan proses pembelajaran bagi peserta didik sangat ditekankan.

Small Group Discussion (SGD) adalah diskusi kelompok kecil (tutorial) merupakan jantung bagi PBL. Kehidupan PBL (aktivitas pembelajaran) bertumpu pada proses tutorial. Didalam proses tutorial ini para peserta didik bersama-sama dengan tutor melakukan pemahaman dan pencarian pengetahuan yang tersimpan di dalam masalah yang tersaji di modul (skenario) melalui langkah-langkah terstruktur guna mencapai tujuan belajar yang telah ditetapkan maupun tujuan belajar yang lebih dari itu (Priyatmodjo, 2010)

Mahasiswa yang masuk pada semester pertama akan mengalami berbagai adaptasi terkait dengan latarbelakang setiap mahasiswa dan metode pembelajaran ini yang berbeda dengan pendidikan sekolah menengah atas (SMA). Perbedaan yang mendasar dalam proses pembelajaran yang biasa yaitu TCL dan sekarang menjadi SCL dengan menggunakan pendekatan PBL melalui tujuh tahapan yang cukup panjang karena memerlukan waktu sampai mendapatkan kesimpulan materi yang dibahas. Selain itu mahasiswa juga dituntut untuk segera beradaptasi dengan lingkungan tempat tinggal mahasiswa berada sekarang. Apabila mereka tidak mampu menghadapi lingkungan baru yang sangat berbeda dengan kondisi di SMA, maka akan timbul keadaan stres pada mahasiswa.

Stres menimbulkan penilaian (appraisal) oleh individu terhadap stimulus lingkungan yang dihadapinya, mengacu pada suatu hubungan antara individu dan lingkungan yang dinilai oleh individu sebagai beban, membahayakan kesejahteraan atau rasa nyaman karena melebihi kemampuan yang dimiliki oleh individu (Mitchell, 2004). Namun demikian, keadaan stres yang berkelanjutan dapat mengakibatkan pada penyesuaian yang buruk, penyakit fisik dan ketidakmampuan mengatasi masalah yang dihadapi oleh individu (Hawari, 2002). Masalah psikologis yang menyebabkan kemampuan adaptasi individu yang buruk, ketidakmampuan fisik sampai timbul penyakit tentunya sangat tidak diharapkan bagi semua pihak baik mahasiswa maupun civitas akademik. 
Tummes, Janssen, \& Landeweerd (2001) mengungkapkan bahwa biasanya seseorang akan merasakan keletihan yang hebat akibat beban kerja yang tinggi dan dukungan sosial yang kurang. Beratnya masalah yang dihadapi mahasiswa dalam menghadapi KBK dengan metode SCL, jika mahasiswa mempunyai daya juang yang tinggi dalam menghadapi stressor yang terjadi maka kondisi stres tidak akan terjadi. Hal ini bila tidak diatasi dengan baik maka mahasiswa calon perawat akan berisiko terjadinya burnout sebagai perawat pelaksana karena akan timbul reaksi fisik yang negatif akibat kondisi stres yang diarasakan selama bekerja (Fagin, Brown, Barlett, Leary, \& Carson, 1995); Cushway, Tyler, \& Nolan, 1996). Begitu juga menurut Dawkins, Depp dan Seltzer (1985) bahwa perawat memiliki risiko tinggi stres terutama perawat jiwa karena kesulitan dalam menghadapi masalah dalam pekerjaannya.

AQ merupakan bentuk kecerdasan selain IQ, SQ, dan EQ yang digunakan untuk menunjukan bagaimana bertahan dan cara mengatasi kesulitan. AQ dapat digunakan untuk menilai sejauh mana seseorang dalam menghadapi masalah rumit. Dengan kata lain AQ dapat digunakan sebagai indikator bagaimana kemampuan seorang dalam bertahan dan keluar dari kondisi yang penuh tekanan serta tantangan (Seery, Holman, \& Silver, 2010).

Ada tiga kemungkinan yang dapat terjadi ketika seorang mahasiswa menjalani KBK dengan metode SCL, yaitu mahasiswa terus berjuang menyelesaikan perkuliahan dan menjadikan masalah yang ada sebagai suatu media untuk memperbaiki diri dan mencari alternatif penyelesaian yang ada. Permasalahan yang terjadi dapat diselesaikan dengan cara yang baik serta menjadikan sebagai pelajaran di masa yang akan datang bila dirinya telah lulus kuliah. Kemungkinan lain mahasiswa mencoba menjalani KBK dengan metode SCL tapi tidak mempunyai cita-cita setelah lulus menjadi seorang Sarjana Keperawatan (S.Kep), yaitu menjadi seorang perawat pelaksana, pendidik, peneliti atau sebagai manajer. Kemungkinan lainnya adalah mahasiswa tidak mau menerima tantangan dalam menghadapi masalah yang terjadi di lingkungan akademik Fakultas Keperawatan.
Stoltz (2000) menyatakan bahwa IQ dan EQ berpengaruh pada kesuksesan seseorang pada kondisi atau situasi normal, namun tidak terlalu berperan dalam kondisi kritis atau situasi penuh kesulitan. Pada kondisi ini AQ dianggap lebih penting pengaruhnya dari kedua konsep sebelumnya, karena AQ merupakan prediktor umum terhadap kesuksesan dan hadir untuk menjembatani konsep IQ dan EQ. Pengaruh AQ dapat meningkatkan kemampuan seseorang untuk lebih kuat dalam menghadapi masalah (Seery, Holman, \& Silver, 2010). Adversity Quotient menggambarkan seberapa baik seseorang dapat bertahan dan mampu mengatasi kesulitan atau siapa yang tenggelam dalam kesulitannya, dapat meramalkan siapa yang dapat melebihi harapan dari potensinya dan siapa yang akan gagal serta memprediksi siapa yang akan menyerah dan siapa yang akan menang. AQ juga dapat diperbaiki secara berkelanjutan pada seseorang sehingga tidak menetap menjadi suatu kepribadian (Dostie \& Jayaraman, 2009; Jayaraman \& Dostie, 2006), oleh karena itu, perlu dilakukan evaluasi secara berkala mengenai perkembangan AQ seseorang (Cronin-Stubbs D \&Brophy E, 1985).

Tinggi rendahnya AQ seseorang menurut Stoltz (2000) tergantung pada 4 aspek yang perlu dikembangkan yaitu CO2RE. Aspek pertama adalah control, seseorang merasakan seberapa besar kendali yang dimilikinya atas peristiwa yang terjadi pada dirinya, aspek yang kedua yaitu origin and ownership, bagaimana seseorang mempertanggungjawabkan akibat dari asal mula kesulitan yang dihadapi. Selain itu, aspek yang ketiga adalah reach, sejauh mana kesulitan yang dihadapi menjangkau bagian-bagian kehidupan dari seseorang, dan aspek yang terakhir adalah endurance, seberapa lama kesulitan yang dihadapi akan berlangsung. Ketika keempat aspek diatas tidak dapat dikendalikan dengan baik oleh mahasiswa maka yang terjadi adalah tingkat stres yang meningkat dan melebar kedalam sebagian aspek kehidupan sehingga dapat berdampak pada penurunan kualitas hidup dan bahkan memperpanjang waktu studi.

Adversity Quotient (AQ) seseorang dapat dikategorikan menjadi Quitter, kelompok yang tidak tahan pada semua situasi dan kondisi yang berisi tantangan, mudah putus 
Nita Fitria : Gambaran Adversity Quotient Mahasiswa Baru

asa dan menarik diri dengan teman-temanya di lingkungan fakultas. Camper yang bersifat banyak perhitungan, walaupun memiliki keberanian menghadapi tantangan namun selalu mempertimbangkan risiko yang akan dihadapi. Kelompok camper tidak berusaha terlalu keras untuk menyelesaikan pekerjaan karena berpendapat sesuatu yang secara terukur akan mengalami risiko, bahkan mereka merasa cukup puas dan berada pada posisi yang aman di dalam lembaga pemasyarakatan. Climber, selalu berfikir dengan berbagai macam kemungkinan dan tidak akan mudah menyerah pada hambatan yang dihadapi. Climber adalah kepribadian yang selalu bersedia mengambil risiko dalam menghadapi semua tantangan, dapat mengatasi rasa takut, mempertahankan visi, memimpin, dan bekerja keras, serta fokus pada usaha untuk tujuan yang ingin dicapai tanpa menghiraukan segala hambatan yang dialaminya sampai pekerjaannya selesai.

Dari uraian tersebut dapat dilihat bahwa pribadi seperti climber yang dibutuhkan seorang mahasiswa keperawatan, seperti yang sudah dijelaskan bahwa frekuensi tantangan, tekanan dan kesulitan yang dihadapi selama proses pendidikan menjadi modal untuk menghadapi masa kerja setelah lulus. Oleh sebab itu, tujuan dari penelitian ini adalah untuk melihat gambaran adversity quotient pada mahasiswa baru yang sedang mengikuti KBK dengan Metode SCL.

\section{Metode Penelitian}

Jenis penelitian yang digunakan adalah metode penelitian deskriptif kuantitatif. Variabel dalam penelitian ini adalah adversity quotient dengan sub variabel pada penelitian ini adalah dimensi yang terdapat pada adversity quotient yaitu: control, origin dan ownership, reach, dan endurance. Keempat dimensi diatas dikenal dengan nama CO2RE. Dimana tingkatan AQ dibagi menjadi climber, camper, quitter dan masa transisi dari ketiga tingkatan.

Populasi dalam penelitian ini adalah semua mahasiswa baru yaitu 157 orang dengan jumlah sampel 142 orang setelah dilakukan teknik sampling total populasi. Instrumen yang digunakan dalam penelitian ini merupakan modifikasi inventori dari uji Adversity Response Profile (ARP) Quick Take ${ }^{\mathrm{TM}}$. Penentuan klasifikasi $A Q$ mahasiswa baru dengan menggunakan teknik menjumlahkan seluruh dimensi CO2RE dari setiap pertanyaan sehingga didapatkan skor untuk setiap tingkatan dengan skor $0-12=$ quitter, 13-24=transisi quitter ke camper, 25-36=camper, 37-48=transisi camper ke climber. $49-60=$ climber. Kemudian hasil ditabulasi dalam distribusi frekuensi untuk setiap tingkatan AQ.

\section{Hasil Penelitian}

Gambaran AQ. pada mahasiswa baru yang sedang mengikuti KBK dengan Metode SCL, yang dilakukan pada 142 orang mahasiswa ditampilkan pada tabel 1. Berdasarkan tabel 1 menunjukan bahwa AQ mahasiswa baru yang sedang mengikuti KBK dengan metode SCL adalah sebagian besar responden yaitu 87 orang mahasiswa $(61,27 \%)$ pada kelompok climber, 50 orang mahasiswa $(35,21 \%)$ pada kelompok transisi camper ke climber, 5 orang mahasiswa $(3,52 \%)$ pada kelompok camper, tidak seorang pun responden yaitu 0 orang $(0.00 \%)$ pada kelompok transisi quitter ke camper dan tidak seorang pun responden yaitu 0 orang $(0.00 \%)$ pada kelompok quitter.

\section{Pembahasan}

Hasil penelitian ini menunjukkan bahwa SAQ mahasiswa baru berada pada kelompok climber. Climber adalah orang yang berhasil mencapai tujuan yang diharapkan. Mereka senantiasa terfokus pada usaha pencapaian tujuan tanpa menghiraukan apapun keadaan yang dialaminya. Selalu memikirkan berbagai macam kemungkinan dan tidak akan pernah terkendala oleh hambatan yang dihadapinya.

Kepribadian climber apabila dikaitkan dengan situasi dan kondisi mahasiswa baru, mahasiswa sudah beradaptasi dengan kurikulum yang ada sehingga stresor pada awal perkuliahan merupakan tantangan bagi sebagian besar mahasiswa. Bila mahasiswa mendapatkan informasi dari angkatan sebelumnya mengenai kendala yang akan dihadapi maka upaya yang dilakukan adalah 
Nita Fitria : Gambaran Adversity Quotient Mahasiswa Baru

Tabel 1 Distribusi Frekuensi AQ Mahasiswa Baru yang sedang Mengikuti Kurikulum Berbasis Kompetensi dengan Metode SCL $(n=142)$

\begin{tabular}{lrl}
\hline \multicolumn{1}{c}{ Adversity Quotient } & f & $\mathbf{\%}$ \\
\hline Climber & 87 & 61,27 \\
Transisi Camper ke Climber & 50 & 35,21 \\
Camper & 5 & 3,52 \\
Transisi Quitter ke Camper & 0 & 0.00 \\
Quitter & 0 & 0.00 \\
\hline
\end{tabular}

mencoba berbagai alternatif sehingga kendala yang ada bisa dijalani dengan baik misalnya meminjam buku literatur dan bahan materi dari angkatan sebelumnya, melakukan diskusi dengan mahasiswa berprestasi pada angkatan sebelumnya mengenai trik-trik agar bisa berhasil mendapatkan nilai yang baik, dan juga menanyakan pada koordinator mata kuliah nilai yang diraih saat proses pembelajaran berlangsung.

Mahasiswa dalam kelompok climber selain melakukan berbagai alternatif yang positif juga selalu mengevaluasi tindakan yang sudah dilakukan sebelumnya dan bila ada kekeliruan maka segera dilakukan perbaikan sebelum nilai kumulatif dikeluarkan oleh koordinator mata kuliah. Jenis perbaikan yang dilakukan oleh mahasiswa diantaranya dengan meminta perbaikan pada koordinator mata kuliah. Adversity Quotient pada kelompok transisi camper ke climber adalah orang yang sudah cukup bertahan menembus tantangan-tantangan. Mereka sudah dapat memanfaatkan potensinya ketika dihadapkan kepada suatu tantangan dan kesulitan yang rumit. Bila dikaitkan dengan situasi dan kondisi mahasiswa, sebagian kecil mahasiswa sudah cukup beradaptasi terhadap kendala yang dirasakan pada proses pembelajaran dengan metode SCL. Kendala yang dirasakan mahasiswa adalah timbul kejenuhan pada saat menggunakan model seven jump. Model ini memerlukan waktu yang cukup lama agar kelompok dapat menentukan Learning Objective (LO) pada setiap kasus. Walaupun demikian, mahasiswa kelompok transisi ini mencoba memanfaatkan potensi dirinya dengan cara membuat suasana diskusi lebih ramai dan aktif sehingga kejenuhan yang dirasakan akan berkurang. Perbedaan antara kelompok climber dan transisi, antara camper ke climber adalah adanya hasrat yang lebih tinggi untuk menemukan LO dan kompetensi yang harus dicapainya sehingga dirinya merasa tidak puas dengan IPK yang sudah diraih, tidak puas dengan materi yang diberikan oleh dosen dalam metode lecture tetapi mencoba mencari tahu sehingga wawasan mahasiswa tersebut terus berkembang dan mampu mengintegrasikan setiap mata kuliah di satu semester tersebut.

Adversity Quotient dengan kelompok campers adalah orang yang berhenti dan tinggal di tengah pendakian. Sifatnya adalah satisfier, merasa puas diri dengan hasil yang sudah dicapai. Apabila dikaitkan dengan situasi dan kondisi mahasiswa, sangat sedikit mahasiswa yang sudah merasa puas dengan hasil IPK yang sudah dicapai sehingga pelaksanaan model seven jump hanya sebuah proses yang tidak bermakna bagi sebagian kecil mahasiswa. Kemungkinan besar hanya sebagian kecil mahasiswa yang merasa puas karena orientasi mahasiswa hanya difokuskan pada pencapaian IPK sebagai laporan untuk orang tua bukan kompetensi yang sudah dicapai setiap mata kuliah.

Adversity Quotient dengan kelompok transisi quitters ke campers adalah orang yang kurang memanfaatkan kemampuan dan peluang yang dimiliki terlebih saat menghadapi tantangan. Mereka menganggap kesulitan adalah sesuatu yang menimbulkan kerugian besar. Pada penelitian ini tidak ada seorang pun mahasiswa yang beranggapan bahwa metode SCL dengan model seven jump dapat memberikan kerugian besar bagi dirinya sendiri. Kemungkinan terdapat faktor pendukung yang tinggi namun mahasiswa pada kelompok transisi ini kurang memanfaatkan dukungan sarana dan prasana yang tersedia di fakultas seperti media untuk mencari literatur dengan internet dan buku literatur yang sudah cukup tersedia di perpustakaan. 
Nita Fitria : Gambaran Adversity Quotient Mahasiswa Baru

Adversity Quotient dengan kelompok camper adalah orang yang berhenti dan tidak berusaha untuk melanjutkan. Berusaha secukupnya lalu berhenti dan mengakhiri pencapaiannya. Sifatnya adalah satisfier, merasa puas diri dengan hasil yang sudah dicapai. Pada penelitian ini tidak ada seorangpun mahasiswa yang beranggapan bahwa metode SCL dengan model seven jump sangat memberatkan bagi mahasiswa. Mahasiswa denganAQ camper memilih untuk keluar dari fakultas keperawatan. Mahasiswa pada kelompok ini menginginkan adanya kemudahan untuk mendapatkan nilai yang baik dan tidak memperdulikan pencapaian kompetensi yang harus diraihnya, protes bahkan bisa sampai mengundurkan diri.

Kemungkinan tidak ada seorang pun mahasiswa baru berada pada kelompok AQ camper ini karena faktor pendukung secara internal maupun ekternal sangat kuat untuk menjalani program SCL tersebut. Faktor pendukung internal ini membedakan dengan kelompok transisi dari quitter ke camper, pada saat pendukung eksternal seperti sarana dan prasarana serta fungsi fasilitator kurang kondusif, maka faktor pendukung internal ini akan memainkan peranan besar dalam mencapai prestasi yang gemilang untuk menjadi seorang perawat profesional.

\section{Simpulan}

Kesimpulan dari hasil penelitian ini bahwa persentase terbesar AQ mahasiswa baru adalah climber, yaitu mahasiswa mampu melihat masalah yang ada saat menjalani program profesi sebagai suatu tantangan, mahasiswa mampu beradaptasi dari kurikulum yang ada pada program akademik sehingga stresor terhadap proses pembelajaran merupakan tantangan bagi sebagian besar mahasiswa. Mahasiswa dengan AQ climber berusaha mendapatkan informasi mengenai kendala yang dihadapi, sehingga mahasiswa dapat melakukan berbagai alternatif untuk mengatasi kendala yang ada.

Hasil penelitian ini, disarankan agar mahasiswa yang telah memiliki AQ pada kelompok climber perlu mempertahankan dan meningkatkan potensi untuk memanfaatkan situasi dan kondisi apapun saat menjalani program profesi ners dan menjadi suatu peluang serta tantangan yang harus dihadapi sehingga kompetensi sebagai perawat profesional dapat diraih.

\section{Daftar Pustaka}

Dostie, B., \& Jayaraman, R. (2009). The effect of adversity on process innovations and managerial incentives. Social Science Research Network, 9(2).

Cronin-Stubbs, D. \& Brophy, E. (1985). Burnout: can social support save the psychiatric nurse? . Journal of Psychosocial nursing and mental health service, 23(7), 8-13.

Cushway, D.,Tyler, P., \& Nolan P. (1996). Development of a stress scale for mental health profesional. British Journal of Clinical Psychology, 2, 279-295.

Dawkins, J. E., Depp, F. \& Seltzer, N. (1985) Stress and the psychiatric nurse. Journal of Psychosocial Nursing, 23, 9-15.

Fagin, L., Brown, D., Barlett, H., Leary, J., \& Carson, J. (1995). The claybury community psychiatric stress survey: Is it more stressful to work in hospital or the community? Journal of Advance Nursing, 22(2), 347-358.

Hawari, D. (2002). Managemen stres, cemas, dan depresi. Jakarta: FK UI Press.

Jayaraman, R., \& Dostie, B. (2006). Determinant of scholl enrollment in Indian villages. Economics Development and Cultural Change. 54 (2), 405-421.

Mitchell, D. (2004). Stress, coping, and appraisal: A test of the goodnes-of-fit hypothesis. Ohio: Ohio University Press.

Priyatmojo, A., Kumara, A., Innaka, A., Achmad, B., Pranowo, D., Widiayati, D. T., . . Prabandari, Y. S. (2010). Buku panduan pelaksanaan student centered learning (SCL) dan student teacher aesthethic role-sharing (STAR). Yogyakarta: Pusat Pengembangan Pendidikan UGM. 
Seery, M. D., Holman, E. A., \& Silver, R. C. (2010). Whatever does not kill us: cumulative lifetime adversity, vulnerability and resilience. Journal of Personality and Social Psychology, 99(6), 1025-1041.

Stoltz, P. G. (2000). Adversity quotient, mengubah hambatan menjadi peluang. Jakarta: Grasindo.

Tummes, G. E. R., Janssen P. P. M., Landeweerd, A. \& Houkes, I. (2001). Stress measure based on a structural equation model. Journal of Advanced Nursing, 36 (1), 151-162. 